\title{
Comportamento alimentar de adultos de Diabrotica speciosa na presença de extratos aquosos de Meliaceae
}

\author{
Feeding behavior of Diabrotica speciosa adults on Meliaceae aqueous extracts
}

\author{
Rita de Cássia Andrade dos Santos Seffrin ${ }^{\mathrm{I}}$ Ervandil Corrêa Costa $^{\mathrm{I}}$ Solon Jonas Longhi ${ }^{\mathrm{II}}$ \\ Sidinei José Lopes ${ }^{\mathrm{II} *}$ Valdecir José dos Santos ${ }^{\mathrm{III}}$
}

\section{RESUMO}

O objetivo do presente experimento foi selecionar extratos com atividade antialimentar sobre Diabrotica speciosa (Germar, 1824). O consumo foliar de insetos adultos foi determinado, em laboratório, sob condições de livre escolha. Folhas de feijoeiro (Phaseolus vulgaris) foram cortadas em formato circular e tratadas com extratos aquosos de folíolos e de pecíolos com caule de: Cedrela fissilis Vell., Cabralea canjerana (Vell.) Mart, Melia azedarach L. var. azedarach, Trichilia claussenii C. DC., Trichilia catigua A. Juss. e Trichilia elegans A. Juss., dispostos em placas de Petri, e um inseto liberado e mantido no interior da placa por 24 horas. A área foliar consumida foi determinada após este período. O extrato de folíolos de M. azedarach var. azedarach apresentou maior efeito antialimentar que o extrato de pecíolos com caule. Entretanto, a área foliar consumida nas folhas tratadas com o extrato de pecíolos com caule foi menor do que nas tratadas com extratos de folíolos, indicando maior efeito antialimentar. $O$ índice KOGAN \& GOEDEN (1970) mostrou efeito fagodeterrente para todos os extratos, mas não mostrou diferenças significativas entre eles.

Palavras-chave: atividade inseticida, preferência alimentar, vaquinha.

\section{ABSTRACT}

The aim of this research was to select extracts with insect antifeedant activity. Leaf consumption by adults of Diabrotica speciosa was determined under laboratory conditions with free choice. Bean leaf had been cut in circular format and treated with aqueous extracts of leaflets, petioles with stems of Cedrela fissilis Vell., Cabralea canjerana (Vell.) Mart, Melia azedarach L. var. azedarach, Trichilia claussenii C. DC., Trichilia catigua A. Juss. e Trichilia elegans A. Juss, arranged in Petri plates, and an insect released and kept within the plate for 24 hours. The consumed leaf area was determined after this period. The leaflet extract of M. azedarach var. azedarach showed greater antifeedant activity tham the extract of petiole with stems. However, the consumed leaf area in the leaves treated with the extract of petioles with stem was lower than in treated with extracts of leaves, giving greater antifeedant effect. The KOGAN \& GOEDEN index (1970) showed antifeedant activity for all the extracts, but did not show significant differences between them.

Key words: insecticide activity, food preference, root worm

\section{INTRODUÇÃO}

Diabrotica speciosa é a principal espécie praga do feijoeiro e de algumas olerícolas no Sul do Brasil (GASSEN, 1993). Quando a população de adultos observada no campo é elevada, nas culturas de feijão e de soja, os agricultores realizam freqüentes pulverizações com inseticidas, no sentido de minimizar o problema (MILANEZ, 1995), o que está levando à contaminação do ambiente e à seleção de populações resistentes ao produto empregado. Esta situação torna evidente a necessidade de métodos de controle alternativos, menos tóxicos e adequados às condições econômicas dos agricultores brasileiros. Uma opção que atende a essas condições é o aproveitamento de plantas com características inseticidas.

A utilização de compostos tóxicos de origem vegetal não é uma técnica recente, já que seu uso no

IDepartamento de Defesa Fitossanitária, Universidade Federal de Santa Maria (UFSM), Santa Maria, RS, Brasil.

IIDepartamento de Ciências Florestais, UFSM, Santa Maria, RS, Brasil.

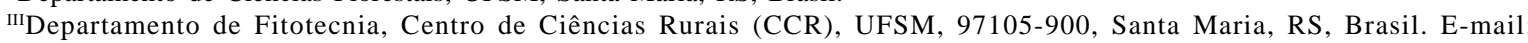

sjlopes@smail.ufsm.br.*Autor para correspondência. 
controle de pragas era bastante comum nos países tropicais antes do advento dos inseticidas sintéticos (VENDRAMIM \& CASTIGLIONI, 2000). Com o surgimento dos inseticidas organossintéticos, os compostos de origem vegetal praticamente deixaram de ser usados. No entatnto, com o passar dos anos, casos documentados de contaminação ambiental e resistência de muitas espécies de pragas a estes produtos incentivaram o desenvolvimento de produtos alternativos com o objetivo de reduzir o impacto ao meio ambiente (SAXENA, 1983).

As pesquisas envolvendo plantas inseticidas evoluíram muito nas últimas décadas em todos os continentes, sendo o maior destaque dado à Azadirachta indica, comumente conhecida por nim. Os resultados verificados com o nim têm estimulado pesquisas com outras plantas da família Meliaceae no intuito de encontrar novas espécies com atividade inseticida (BOGORNI, 2003).

Em estudos realizados com extratos aquosos a 10\% de pó-fumo, ramo e folhas de cinamomo, verificouse o controle de larvas de Microtheca ochroloma, ocasionando mortalidade superior a $80 \%$ a partir do terceiro dia de exposição dos insetos ao pó-de-fumo e ao ramo de cinamomo e do quarto dia ao de folha de cinamomo (DEQUECH et al., 2008). Segundo SOUZA \& VENDRAMIM (2001), efeitos de extratos de frutos verdes e de folhas de $\boldsymbol{M}$. azedarach apresenta efeito ovicida sobre Bemisia tabaci. Os mesmos autores verificaram também redução da sobrevivência ninfal com o uso de extratos de frutos verdes, frutos maduros e folhas desta espécie. Já para extratos de Trichilia pallida, os ramos foram a única estrutura que afetaram a mortalidade de ovos e a sobrevivência ninfal de B. tabaci

O efeito produzido pela estrutura vegetal pode ser avaliado utilizando o índice de preferência alimentar de KOGAN \& GOEDEN (1970), sendo classificado como fagoestimulante se o índice for maior do que um, neutro se igual a um, e fagodeterrente se foi menor do que um.

A orientação para plantas potencialmente hospedeiras e a discriminação de uma planta hospedeira de uma não-hospedeira requer um sistema sensorial altamente desenvolvido. Se o estímulo recebido pelo inseto for positivo, ele se dirigirá até a planta e a substância que provocou esse estímulo será chamada de atraente. Caso contrário, em presença de um repelente, o inseto se dirigirá em direção contrária à direção da planta. Uma vez em contato com a planta, se o inseto receber um estímulo positivo, ele realizará a picada ou a mordida de prova e, nesse caso, a substância que provocou o estímulo receberá o nome de incitante. Caso contrário, em presença de um supressor, o inseto não dará a picada ou a mordida de prova e se afastará da planta. Após o início da alimentação, se o inseto for estimulado a manter-se alimentando, a substância será chamada de fagoestimulante. Se o inseto for induzido a paralisar a alimentação, a substância provocadora deste estímulo será chamada de fagodeterrente (VENDRAMIM \& CASTIGLIONI, 2000).

O consumo elevado de uma planta nem sempre representa vantagens aos insetos porque pode aumentar a ingestão de aleloquímicos, podendo ter efeitos danosos ao desenvolvimento dos mesmos (SIMPSON \& SIMPSON, 1990). Estudos relacionados ao comportamento alimentar dos insetos-praga podem fornecer informações que auxiliam no desenvolvimento de novas formas de controle (ÁVILA \& PARRA, 2003).

Assim, este trabalho teve como objetivo avaliar o comportamento alimentar de adultos de $\boldsymbol{D}$. speciosa na presença de extratos de plantas da família Meliaceae, visando fornecer informações que auxiliem no controle alternativo deste inseto-praga.

\section{MATERIAL E MÉTODOS}

O experimento foi conduzido no Laboratório do Departamento de Defesa Fitossanitária, da Universidade Federal de Santa Maria, Santa Maria, Rio Grande do Sul, Brasil, à temperatura de $25 \pm 2^{\circ} \mathrm{C}$, umidade relativa $60 \pm 10 \%$ e fotofase de 14 horas (MILANEZ, 1995). Os tratamentos foram: folíolos e pecíolos com caule de Cedrela fissilis, Cabralea canjerana, Melia azedarach var. azedarach, Trichilia claussenii, Trichilia catigua e Trichilia elegans e testemunha. As plantas foram coletadas na região de Santa Maria, em outubro de 2003.

Os pecíolos com caule foram moídos sem proceder a secagem. Os folíolos foram secos à temperatura ambiente, sendo posteriormente moídos no liquidificador até obtenção de pó. Para o preparo dos extratos na concentração de $1 \%(\mathrm{p} / \mathrm{v})$, fez-se imersão em água destilada e agitação para homogeneizar as amostras (BOGORNI, 2003). Foram mantidas em repouso por 24 horas na geladeira para extração dos compostos com atividade inseticida. Posteriormente realizou-se a filtragem com tecido tipo voil para a retirada do material sólido.

Teste com chance de escolha foi realizado entre substrato (discos de folhas de feijoeiro tratadas com extrato) e substrato não-tratado (testemunha), em placas de Petri de nove centímetros de diâmetro, com o fundo recoberto por gesso umedecido e sobre este foi colocado papel-filtro (BOGORNI, 2003). Discos de folhas de feijoeiro, obtidos com vazador de um 
centímetro de diâmetro, foram colocados na placa de Petri, sendo dois tratados com extrato e dois com água destilada (testemunha), dispostos aos pares de forma cruzada e eqüidistante. Para cada extrato vegetal, foram utilizadas 15 placas de Petri, cada uma representando uma repetição. Insetos adultos de Diabrotica speciosa foram coletados na área experimental do Departamento de Fitotecnia e posteriormente foram colocados no centro de cada placa. Após 24 horas, retirou-se o inseto e a área dos discos foi escaneada e medida com o auxílio do software Sigma Scan Pro v. 5.0 (Jandel Scientific, San Rafael, CA). O consumo foliar por inseto foi obtido pela diferença entre a área inicial da folha e a área que restou.

Com base nos valores das áreas consumidas pelo inseto, foi calculado o índice de preferência adaptado por KOGAN \& GOEDEN (1970), IP=2A/ (M+A), em que: $\mathrm{A}=$ área consumida nos discos tratados, e $\mathrm{M}=$ área consumida nos discos não-tratados. Foram avaliadas as variáveis área consumida dos discos de folhas tratadas $\left(\mathrm{cm}^{2}\right)$, área consumida dos discos não tratados (testemunha) ( $\left.\mathrm{cm}^{2}\right)$ e índice de preferência (IP), para as quais procedeu-se análise de variância e posterior teste de médias Scott-Knott com 5\% de probabilidade de erro.

\section{RESULTADOS E DISCUSSÃO}

Os resultados obtidos indicam um predomínio dos insetos em consumir folhas de feijoeiro tratadas com extrato de folíolos do que com extrato de pecíolos com caule (Tabela 1), com exceção de $\boldsymbol{C}$. canjerana, M. azedarach var. azedarach e T. elegans, cujo extrato de folíolos não apresentou diferença significativa do extrato de pecíolo com caule, demonstrando o efeito inseticida dessas duas espécies. Resultado semelhante foi encontrado com extratos de Nim (Azadiractha indica) e Cinamomo (Melia azedarach), em mosca-das-frutas (Anastrepha fraterculus) por meio da redução da postura, do desenvolvimento larval e pupal (SALLES et al., 1999).

Pode-se observar na figura 1 que o percentual da área consumida na testemunha e nas folhas de feijoeiro tratadas com o extrato de pecíolo com caule de $\boldsymbol{M}$. azedarach var. azedarach foi menor em relação aos demais tratamentos, mas o índice de preferência foi o mais elevado. Este resultado pode indicar que o inseto, ao se alimentar das folhas com extrato, está ingerindo aleloquímicos que podem inibir a alimentação logo após a mordida de prova ou que os compostos presentes no extrato tenham causado uma toxicidade subletal no mesmo. Este é o extrato que possui maior efeito fagodeterrente. Em um trabalho desenvolvido em Recife, PE, TORRES et al. (2001) verificou que a duração da fase larval de $\boldsymbol{P}$. xylostella foi afetada pelos extratos aquosos de M. azedarach, em que as larvas que se alimentaram de folhas impregnadas com o extrato vegetal tiveram um alongamento dessa fase em 3,5 dias. Esta influência dos extratos aquosos na redução da viabilidade da fase pupal de $\boldsymbol{P}$. xylostella mostrou-se eficiente.

Os extratos aquosos obtidos de $\boldsymbol{M}$. azedarach var. azedarach e das Trichilia sp. demonstraram bioatividade sobre o comportamento alimentar da $\boldsymbol{D}$. speciosa (Tabela 1), com redução significativa no consumo de folhas de feijoeiro, quando

Tabela 1 - Média das áreas de dois discos de folhas de feijoeiro $\left(\mathrm{cm}^{2}\right)$ consumidas por Diabrotica speciosa tratadas com extratos aquosos de meliáceas a 1\%, em laboratório. Santa Maria, RS, 2003.

\begin{tabular}{|c|c|c|c|}
\hline \multirow{2}{*}{ Extratos } & \multicolumn{2}{|c|}{ Área consumida $\left(\mathrm{cm}^{2}\right)$} & \multirow{2}{*}{ Índice de preferência (IP) } \\
\hline & discos de folhas tratadas & testemunha & \\
\hline Folíolos de Cedro rosa- $\boldsymbol{C}$. fissilis & $0,2572 \mathrm{a}^{*}$ & 0,4497 a & $0,7277 \mathrm{a}$ \\
\hline Folíolos de Catiguá- T. catigua & $0,1673 \mathrm{~b}$ & $0,2136 \mathrm{~b}$ & 0,8784 a \\
\hline Folíolos de Catiguá vermelho- $\boldsymbol{T}$. claussenii & $0,1294 \mathrm{~b}$ & $0,2233 \mathrm{~b}$ & 0,7338 a \\
\hline Folíolos de Cinamomo- M. azedarach var. azedarach & $0,0842 \mathrm{c}$ & $0,2813 \mathrm{~b}$ & $0,4607 \mathrm{a}$ \\
\hline Folíolos de Canjerana- C. canjerana & $0,0683 \mathrm{c}$ & 0,1622 c & 0,5926 a \\
\hline Folíolos de Pau ervilha- T. elegans & $0,0572 \mathrm{c}$ & 0,2925 c & 0,3271 a \\
\hline Pecíolos com caules de Canjerana- $\boldsymbol{C}$. canjerana & $0,0444 \mathrm{c}$ & $0,0509 \mathrm{c}$ & 0,9318 a \\
\hline Pecíolos com caules de Cedro rosa- $\boldsymbol{C}$. fissilis & $0,0411 \mathrm{c}$ & $0,1018 \mathrm{c}$ & 0,5752 a \\
\hline Pecíolos com caules de Cinamomo- $\boldsymbol{M}$. azedarach var. azedarach & $0,0371 \mathrm{c}$ & $0,0486 \mathrm{c}$ & 0,8658 a \\
\hline Pecíolos com caules de Pau ervilha- T. elegans & $0,0358 \mathrm{c}$ & 0,1255 c & 0,4439 a \\
\hline Pecíolos com caules de Catiguá- $\boldsymbol{T}$. catigua & $0,0348 \mathrm{c}$ & $0,0878 \mathrm{c}$ & $0,5677 \mathrm{a}$ \\
\hline Pecíolos com caules de Catiguá vermelho- $\boldsymbol{T}$. claussenii & 0,0247 c & $0,0614 \mathrm{c}$ & 0,5738 a \\
\hline
\end{tabular}

* Médias não seguidas pela mesma letra, nas colunas, diferem significativamente pelo teste de Scott-Knott a 5\% de probabilidade de erro; \# $\mathrm{IP}=2 \mathrm{~A} /(\mathrm{M}+\mathrm{A})$; em que $\mathrm{A}=$ área consumida dos discos tratados; e, $\mathrm{M}=$ áreas consumidas nos discos não-tratados. 


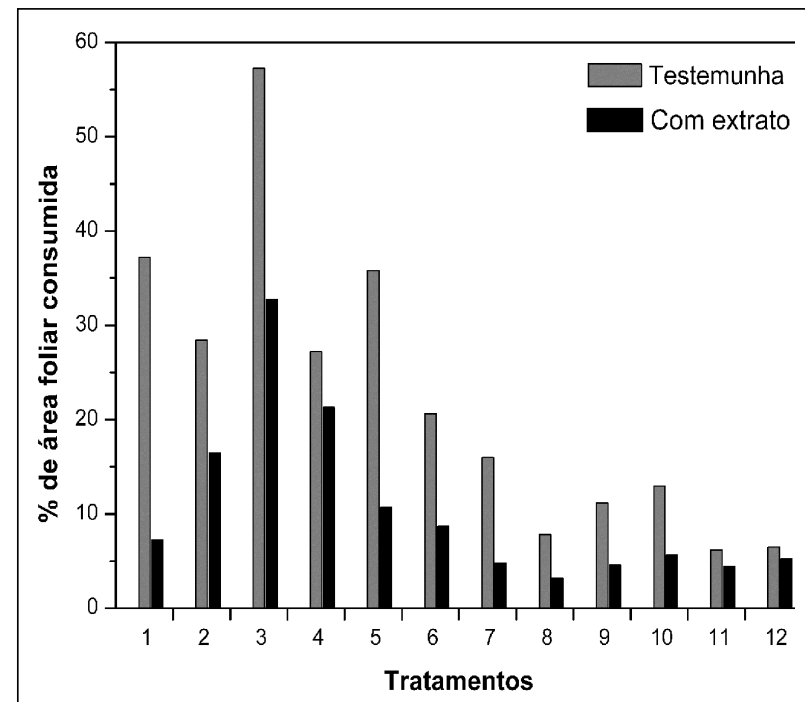

Figura 1 - Média das áreas consumidas por D. speciosa em folhas de feijoeiro tratadas com extratos aquosos a $1 \%$. Santa Maria-RS, 2003. Folíolos de: T. elegans (1), T. claussenii (2), C. fissilis (3), T. catigua (4), M. azedarach var. azedarach (5), C. canjerana (6); Pecíolos com caule de: T. elegans (7), T. claussenii (8), T. catigua (9), C. fissilis (10), M. azedarach var. azedarach (11) e $\boldsymbol{C}$. canjerana (12).

comparadas com a testemunha (não-tratada). Essa atividade inseticida de extratos aquosos das Meliaceas M. azedarach e Trichilia sp. também foi verificada por SOUZA \& VENDRAMIM (2000) que, em concentrações variáveis entre 1 e $3 \%$, obteve efeito ovicida sobre Bemisia tabaci, biótipo B., porém, a duração da fase imatura do inseto não foi afetada.

O índice de preferência alimentar é eficiente em estudos de consumo foliar por insetos, mas não mostrou eficiência para estudos que visem selecionar melhores extratos de plantas com efeito inseticida. $\mathrm{Na}$ tabela 1, é possível observar que todos os extratos apresentaram efeito fagodeterrente, no entanto, não houve diferença significativa para o IP, apesar de verificarmos valores muito baixos de área foliar consumida devido aos efeitos dos extratos estudados.

\section{CONCLUSÕES}

Os extratos aquosos das espécies Cabralea canjerana, Cedrela fissilis, Melia azedarach L. var. azedarach, Trichilia catigua e Trichilia elegans apresentaram efeito fagodeterrente pelo índice de preferência de KOGAN \& GOEDEN (1970), não havendo diferenças significativas entre eles.

Extratos de pecíolos e caules apresentaram maior efeito antialimentar sobre $\boldsymbol{D}$. speciosa não sendo possível selecionar o melhor extrato. Assim, são necessários estudos complementares visando esta seleção.

\section{REFERÊNCIAS}

ÁVILA, C.J; PARRA, J.R.P. Leaf consumption by Diabrotica speciosa (Coleoptera:Chrysomelidae) adults on different host plants. Scientia Agricola, v.60, p. 789792, 2003.

BOGORNI, P.C. Efeito de extratos aquosos de Trichilia spp. sobre o desenvolvimento de Spodoptera frugiperda (J. E. Smith) em milho. 2003. 65f. Tese (Doutorado em Ciências) - Escola Superior de Agricultura Luiz de Queiroz, Universidade de São Paulo, Piracicaba, São Paulo.

DEQUECH, S.T.B. et al. Efeito de extratos de plantas com atividade inseticida no controle de Microtheca ochroloma Stal (Col.: Chrysomelidae), em laboratório. Biotemas, v.21, p.41-46, 2008.

GASSEN, D.N. Parasitismo em adultos de Diabrotica speciosa na região do planalto do Rio Grande do Sul. In: REUNIÃO SUL-BRASILEIRA DE INSETOS DE SOLO, 1993, Passo Fundo. Anais e Ata... Passo Fundo: EMBRAPA/CNPT/ SEB, 1993. V.1. 176p. p.147.

KOGAN M.; GOEDEN, R.D. The host-plant range of Lema trilineata daturaphila (Coleoptera: Chrysomelidae). Annals of Entomological Society of America, v.63, p.1175-1180, 1970.

MILANEZ, J.M. Técnicas de criação e bioecologia de Diabrotica speciosa (Germar, 1824) (Coleoptera: Chrysomelidae). 1995. 102f. Tese (Doutorado em Ciências), Escola Superior de Agricultura Luiz de Queiroz, Universidade de São Paulo, Piracicaba, São Paulo.

SALLES, L.A. et al. Efeito de extratos de Nim (Azadiractha indica) e cinamomo (Melia azedarach) sobre Anastrepha fraterculus (Wied.) (DIPTERA:TEPHRITIDAE). Revista Brasileira de Agrociência, v.5, n.3 p.225-227, 1999.

SAXENA, R.C. Naturally occuring pesticides and their potential. In: SHEMILT, L.W. (Ed.) Chemistry and world food supplies. Oxford: Pergamon, 1983. 664p.

SIMPSON, S.L.; SIMPSON, C.L. Mechanisms of compensation by phytophagous insects. In: BERNAYS, E.A. (Ed.). Focus on insect-plant interactions. Boca Raton: CRC, 1990. p. $111-160$

SOUZA, A.P.; VENDRAMIM, J.D. Atividade inseticida de extratos aquosos de meliáceas sobre a mosca branca Bemisia tabaci (Gennadius) Biótipo B (Hemiptera: Aleyrodidae). Neotropical Entomology, v.31, p.133-137, 2001.

SOUZA, A.P.; VENDRAMIM, J.D. Atividade ovicida de extratos aquosos de meliáceas sobre a mosca branca Bemisia tabaci (Gennadius) Biótipo B em tomateiro. Scientia Agricola, Piracicaba, v.57, n.3, p.403-406, 2000.

TORRES, A.L. et al. Efeito de extratos aquosos de plantas no desenvolvimento de Plutella xylostella (L.) (Lepidoptera: Plutellidae). Neotropical Entomology, v.30, p.151-156, 2001.

VENDRAMIM, J.D.; CASTIGLIONI, E. Aleloquímicos, resistência de plantas e plantas inseticidas. In: CASTIGLIONI, E. (Ed.). Bases e técnicas do manejo de insetos. Santa Maria: Pallotti, 2000. p.113-128. 